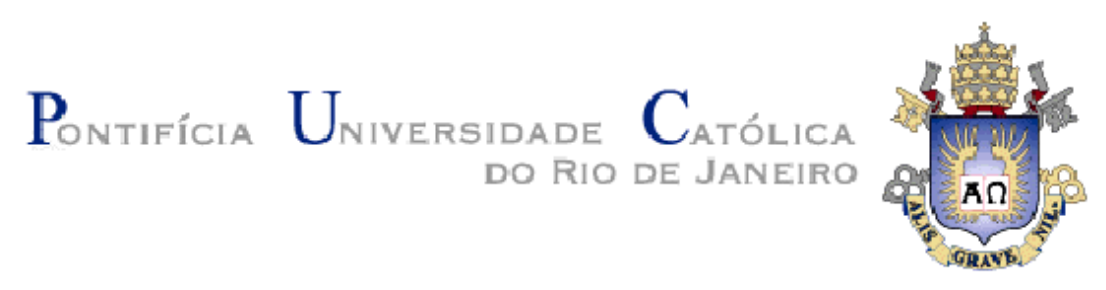

Maria Stella Nunes de Oliveira

Síntese e Caracterização de Complexos Envolvendo Poliaminas e os Íons Metálicos Zinco (II), Níquel (II) e Paládio (II)

\begin{abstract}
Dissertação de Mestrado
Dissertação apresentada ao Programa de Pós-Graduação em Química da PUC-Rio como requisito parcial para obtenção do título de Mestre em Química.
\end{abstract}

Orientadora: Prof. Judith Felcman Co-orientadora: Prof. Bárbara Lúcia Almeida

Rio de Janeiro Fevereiro de 2010 


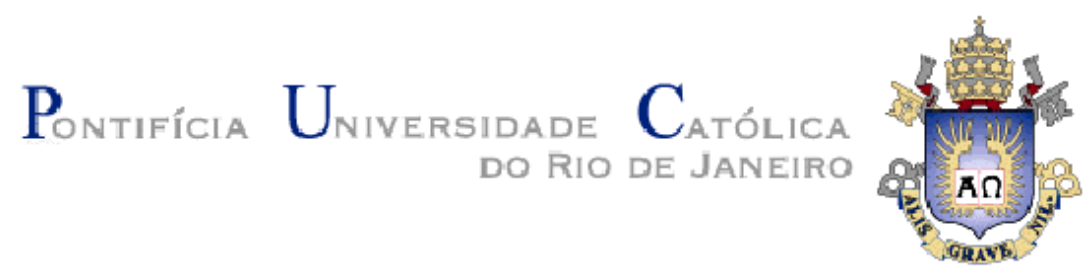

Maria Stella Nunes de Oliveira

\title{
Síntese e Caracterização de Complexos Envolvendo Poliaminas e os Íons Metálicos Zinco (II), Níquel (II) e Paládio (II)
}

Dissertação apresentada ao Programa de Pós-Graduação em Química da PUC-Rio como requisito parcial para obtenção do título de Mestre em Química. Aprovada pela Comissão Examinadora abaixo assinada.

\author{
Prof. Judith Felcman \\ Orientadora \\ Departamento de Química - PUC-Rio \\ Prof. Bárbara Lúcia de Almeida \\ Co-orientadora \\ UFJF
}

Prof. Andréa de Moraes Silva

IFRJ

Prof. Otavio Versiane Cabral

IFRJ

Prof. José Eugenio Leal Coordenador Setorial de Pós-Graduação do

Centro Técnico Científico - PÜC-Rio

Rio de Janeiro, 25 de fevereiro de 2010 
Todos os direitos reservados. É proibida a reprodução total ou parcial do trabalho sem autorização da Universidade, da autora e da orientadora.

\section{Maria Stella Nunes de Oliveira}

Graduou-se em Licenciatura em Química no CEFET Química atual Instituto Federal de Educação, Ciência e Tecnologia do Rio de Janeiro em 2007. Durante a graduação teve bolsa de estágio curricular no Museu da Vida da Fundação Oswaldo Cruz no período de 2005 a 2006 e foi aluna de Iniciação Científica do CEFET Química no período de 2006 a 2007, desenvolvendo trabalhos na área de Química Bioinorgânica.

Ficha Catalográfica

Oliveira, Maria Stella Nunes de

Síntese e caracterização de complexos envolvendo poliaminas e os íons metálicos zinco (II), níquel (II) e paládio (II) / Maria Stella Nunes de Oliveira; orientadora: Judith Felcman; coorientadora: Bárbara Lúcia Almeida - 2010.

196 f. : il. (color.) ; $30 \mathrm{~cm}$

Dissertação (Mestrado)-Pontifícia Universidade Católica do Rio de Janeiro, Departamento de Química, 2010.

Inclui bibliografia

1. Química - Teses. 2. Poliaminas. 3. Complexos de zinco (II). 4. Complexos de níquel (II). 5. Complexos de paládio (II). I. Felcman, Judith. II. Almeida, Bárbara Lúcia. III. Pontifícia Universidade Católica do Rio de Janeiro. Departamento de Química. IV. Título.

CDD: 540 
A Deus, pelas bênçãos que recebo todos os dias de suas mãos.

Aos meus pais e ao meu irmão pelo incentivo, amor e compreensão. 


\section{Agradecimentos}

A Deus, pelo dom da vida e pelas inúmeras bênçãos que dispõe em minha vida.

À professora Judith Felcman pela disponibilidade da orientação, pela paciência, pelo companheirismo, pela compreensão e, principalmente, pela forma amável que trata todos os seus alunos.

À Professora Bárbara Lúcia de Almeida pela amizade, pela dedicação, pela paciência e pelos ricos e fundamentais ensinamentos transmitidos.

À minha família e aos meus amigos que tanto torceram por mim, colaborando com estímulo e amizade, elementos fundamentais para essa conquista.

Aos amigos Leonardo e Aline que são como irmãos. Juntos superamos dificuldades na graduação e no mestrado. Apoiamo-nos na hora das tristezas e lamentações e nos alegramos na hora das conquistas. Estudamos muuuuiiiito! E sempre juntos! Pela amizade, pelo companheirismo e pela alegria de estarmos juntos, o meu agradecimento.

A todos os amigos da PUC-Rio, entre eles, Joanna, Pedro, Vanessa, Natalie, Felipe e todos os outros, pelo companheirismo e pela amizade. 
Às amigas Luciana e Luciene da PUC-Rio pelo companheirismo, pela generosidade e pelo carinho. Conhecer pessoas como vocês faz com que eu tenha certeza de que determinadas pessoas são realmente anjos que Deus coloca no mundo para iluminar a vida dos outros.

À Professora Andréa de Moraes Silva que, com sua doçura e seu rigor, despertou em meu coração o desejo de estudar Química Inorgânica.

Ao técnico Jorge, pelo auxílio na espectroscopia de infravermelho e na análise termogravimétrica. Ao técnico Caio, pela assistência na análise elementar. Ao Químico Rodrigo e ao técnico Willian pela ajuda na espectroscopia de absorção atômica.

À Dra. Érika e à FIOCRUZ pelos espectros de Ressonância Magnética Nuclear.

Ao Dr. Ernesto Lang e ao Dr. Davi Fernando Back da Universidade Federal de Santa Maria, pela contribuição fundamental com a Cristalografia de Raios-X.

A todos os professores e funcionários do Departamento de Química da PUC-Rio que direta ou indiretamente contribuíram para a execução deste trabalho, em especial à Secretária da Pós-Graduação Maria de Fátima que, com sua amabilidade, conquista a todos.

Aos membros da banca examinadora pela análise do trabalho.

À PUC-Rio pela oportunidade e pelos auxílios concedidos. 


\section{Resumo}

Oliveira, Maria Stella Nunes de; Felcman, Judith. Síntese e Caracterização de Complexos Envolvendo Poliaminas e os Íons Metálicos Zinco (II), Níquel (II) e Paládio (II). Rio de Janeiro, 2010. 196p. Dissertação de Mestrado - Departamento de Química, Pontifícia Universidade Católica do Rio de Janeiro.

O presente trabalho descreve a síntese e a caracterização de treze complexos envolvendo as poliamina etilenodiamina, diaminopropano, diaminobutano, espermidina e espermina e os íons metálicos Zn (II), Ni (II) e Pd (II). Todas as sínteses foram realizadas em água, um solvente de importância biológica, e em condições próximas às fisiológicas, com o objetivo de mimetizar as ligações e compreender como ocorre a interação das poliaminas com ânions no ciclo biológico, haja vista que em $\mathrm{pH}$ fisiológico essas moléculas se encontram primordialmente na forma protonada e interagem com biomoléculas aniônicas, entre essas, determinados sítios do DNA. Utilizou-se para a caracterização dos complexos as técnicas de condutivimetria, análise elementar, espectrometria de absorção atômica, análise termogravimétrica, espectroscopia no infravermelho, espectroscopia de ressonância magnética nuclear de Hidrogênio e Carbono 13 (para os complexos de zinco), difratometria de Raio-X (para os cristais de zinco), entre outras. Inicialmente foram sintetizados os complexos do tipo (poliamina $\left[\mathrm{ZnCl}_{4}\right]$ ) e, posteriormente, compostos análogos de íon níquel (II) de estequiometria (poliamina[ $\left.\mathrm{NiCl}_{4}\right]$ ). Observou-se que nesses complexos, as poliaminas interagem com o ânion tetraclorometalato (II) através de ligações de hidrogênio. Essas interações ocorrem entre o hidrogênio da amina primária e o cloro da esfera de coordenação. Os complexos formados pelo íon metálico paládio (II) apresentaram, conforme as análises realizadas, estruturas químicas distintas dos demais compostos. Neste caso, foram obtidos os complexos $\left[\mathrm{Pd}(\mathrm{Cl})_{2}\left(\mathrm{C}_{2} \mathrm{H}_{8} \mathrm{~N}_{2}\right)\right],\left[\mathrm{Pd}(\mathrm{Cl})_{2}\left(\mathrm{C}_{3} \mathrm{H}_{10} \mathrm{~N}_{2}\right)\right]$ e $\left[\mathrm{Pd}_{2}(\mathrm{Cl})_{4}\left(\mathrm{C}_{10} \mathrm{H}_{27} \mathrm{~N}_{4}\right)\right]$, que apresentam importância como possíveis fármacos para o tratamento do câncer.

\section{Palavras-chave}

Poliaminas; Complexos de zinco (II); Complexos de níquel (II); Complexos de paládio (II) 


\section{Abstract}

Oliveira, Maria Stella Nunes de; Felcman, Judith. Synthesis and Characterization of Complexes Involving polyamines and the metal ions Zinc (II), Nickel (II) and Palladium (II). Rio de Janeiro, 2010. 196p. MSc. Dissertation - Departamento de Química, Pontifícia Universidade Católica do Rio de Janeiro.

This paper describes the synthesis and characterization of thirteen complexes involving the polyamines ethylenediamine, diaminopropane, diaminobutane, spermidine and spermine, and the metal ions Zn (II), Ni (II) and Pd (II). All syntheses were performed in water, a solvent of biological importance, and under near-physiological changes in order to mimic the bonds and understand the interaction of polyamines with anions in the biological cycle. At physiological $\mathrm{pH}$ these molecules are primarily in the protonated form and interact with anionic molecules, among which certain DNA sites. The complexes were characterized by the techniques of conductivity, elemental analysis, atomic absorption spectrometry, thermogravimetric analysis, infrared spectroscopy, nuclear magnetic resonance of Hydrogen and Carbon 13 (for the zinc complexes), and Xray diffraction (for zinc crystals). The complexes of the type (polyamine $\left[\mathrm{ZnCl}_{4}\right]$ ) were synthesized first and, subsequently, analogous compounds of ion nickel (II) with stoichiometry (polyamine $\left[\mathrm{NiCl}_{4}\right]$ ) were synthesized. It was observed that in these complexes, the polyamines interact with the tetrachlorometalate (II) anion via hydrogen bonds. These interactions occur between the primary amine hydrogen and the chlorine from the coordination sphere. The metal ion complexes formed by palladium (II) showed, as the analysis data, chemical structures distinct from the other compounds. In this case, we obtained the complex $\left[\mathrm{Pd}(\mathrm{Cl})_{2}\left(\mathrm{C}_{2} \mathrm{H}_{8} \mathrm{~N}_{2}\right)\right], \quad\left[\mathrm{Pd}(\mathrm{Cl})_{2}\left(\mathrm{C}_{3} \mathrm{H}_{10} \mathrm{~N}_{2}\right)\right]$ e $\left[\mathrm{Pd}_{2}(\mathrm{Cl})_{4}\left(\mathrm{C}_{10} \mathrm{H}_{27} \mathrm{~N}_{4}\right)\right]$, which have importance as potential drugs for the treatment of cancer.

\section{Keywords}

Polyamines; Zinc Complexes; Nickel Complexes; Palladium Complexes. 


\section{Sumário}

1. Introdução 20

$\begin{array}{ll}\text { 1.1. Objetivos do presente estudo } & 21\end{array}$

2. Natureza das Poliaminas 22

2.1. Aspectos Químicos 22

2.2. Aspectos Biológicos 23

3. Natureza dos Íons Metálicos $\quad 30$

3.1. Aspectos Químicos do Zinco 30

3.1.1 Descrição do Metal 30

3.1.2 Abundância e Ocorrência 30

3.1.3. Usos 30

3.1.4. Propriedades Químicas 31

3.1.5. Ânion Tetraclorozincato $\left[\mathrm{ZnCl}_{4}\right]^{2-} \quad 33$

3.2. Aspectos Bioquímicos do Zinco 33

3.2.1. Enzimas 35

3.2.1.1. Anidrase Carbônica 35

3.2.1.2. Álcool Desidrogenase 37

3.3. Aspectos Químicos do Níquel 42

3.3.1. Descrição do Metal 42

3.3.2. Abundância e Ocorrência 42

3.3.3. Usos 43

3.3.4. Propriedades Químicas 43

3.3.5. Ânion Tetracloroniquelato $\left[\mathrm{NiCl}_{4}\right]^{2-}$

3.3.6. Termocromismo 45

3.4. Aspectos Bioquímicos do Níquel 47

3.4.1. Enzimas 50

3.4.1.1. Urease 50

3.4.1.2. Hidrogenase 51 
3.4.1.3. Monóxido de Carbono desidrogenase

3.5. Aspectos Químicos do Paládio 55

3.5.1. Descrição do Metal 55

3.5.2. Abundância e Ocorrência 55

3.5.3. Usos 55

3.5.4. Propriedades Químicas $\quad 55$

3.6. Aspectos Farmacológicos do Paládio 56

4. Parte Experimental 59

4.1. Materiais e Métodos 59

4.1.1. Lista de Reagentes e Solventes 59

4.1.2. Equipamentos 60

4.2. Ligantes 62

4.2.1. Nomes Oficiais 62

4.2.2. Estrutura das Poliaminas 62

4.2.3. Dados Experimentais 63

4.2.3.1. Informações Gerais sobre as Poliaminas 63

4.3. Complexos de Zinco (II) 64

4.3.1. Síntese dos compostos binários tetraclorozincatos $\mathrm{PA}\left[\mathrm{ZnCl}_{4}\right] \quad 64$

4.3.2. Dados Experimentais 65

4.3.2.1. Informações Gerais sobre os compostos binários tetraclorozincatos $\mathrm{PA}\left[\mathrm{ZnCl}_{4}\right]$

4.4. Complexos de Níquel (II) 67

4.4.1. Síntese dos compostos binários tetracloroniquelatos $\mathrm{PA}\left[\mathrm{NiCl}_{4}\right] \quad 67$

4.4.2. Dados Experimentais 68

4.4.2.1. Informações Gerais sobre os compostos binários tetracloroniquelatos $\mathrm{PA}\left[\mathrm{NiCl}_{4}\right] \quad 68$

4.5. Complexos de Paládio (II) 70

4.5.1. Síntese dos complexos $\left[\mathrm{Pd}(\mathrm{Cl})_{2}\left(\mathrm{C}_{2} \mathrm{H}_{8} \mathrm{~N}_{2}\right)\right]$, $\left[\mathrm{Pd}(\mathrm{Cl})_{2}\left(\mathrm{C}_{3} \mathrm{H}_{10} \mathrm{~N}_{2}\right)\right]$ e $\left[\mathrm{Pd}_{2}(\mathrm{Cl})_{4}\left(\mathrm{C}_{10} \mathrm{H}_{27} \mathrm{~N}_{4}\right)\right] \quad 70$

4.5.2. Dados Experimentais 71

4.5.2.1. Informações Gerais sobre os complexos $\left[\mathrm{Pd}(\mathrm{Cl})_{2}\left(\mathrm{C}_{2} \mathrm{H}_{8} \mathrm{~N}_{2}\right)\right]$, $\left[\mathrm{Pd}(\mathrm{Cl})_{2}\left(\mathrm{C}_{3} \mathrm{H}_{10} \mathrm{~N}_{2}\right)\right]$ e $\left[\mathrm{Pd}_{2}\left(\mathrm{Cl}_{4}\left(\mathrm{C}_{10} \mathrm{H}_{27} \mathrm{~N}_{4}\right)\right] \quad 71\right.$ 
5. Resultados e Discussão 72

5.1. Compostos binários tetraclorozincatos $\mathrm{PA}\left[\mathrm{ZnCl}_{4}\right]$

5.1.1. Geral 73

5.1.2. Ponto de Fusão 75

5.1.3. Condutivimetria 76

5.1.4. Análise Elementar ( $\mathrm{CHN}$ ) e Espectrometria de Absorção Atômica 77

5.1.5. Análise Termogravimétrica 79

5.1.6. Espectroscopia no Infravermelho 83

5.1.7. Espectroscopia Raman 86

5.1.8. Espectroscopia no Ultravioleta-Visível 87

5.1.9. Espectroscopia de Ressonância Magnética Nuclear de Hidrogênio e $\begin{array}{ll}\text { Carbono } 13 & 89\end{array}$

5.1.9.1. Espectroscopia de Ressonância Magnética Nuclear de Hidrogênio $\quad 89$

5.1.9.2. Espectroscopia de Ressonância Magnética Nuclear de Carbono 13

5.1.10. Difratometria de Raios-X 95

5.1.11. Particularidade do Composto Spd[ZnCl$]$

5.2. Compostos binários tetracloroniquelatos $\mathrm{PA}\left[\mathrm{NiCl}_{4}\right]$

5.1.1. Geral 98

5.1.2. Ponto de Fusão 100

5.1.3. Condutivimetria 102

5.1.4. Análise Elementar $(\mathrm{CHN})$ e Espectrometria de Absorção Atômica 104

5.1.5. Análise Termogravimétrica 106

5.1.6. Espectroscopia no Infravermelho 110

5.1.7. Espectroscopia Raman 112

5.1.8. Particularidade do Composto Spd[$\left[\mathrm{NiCl}_{4}\right]$

5.3. Complexos de Paládio (II) - $\left[\mathrm{Pd}(\mathrm{Cl})_{2}\left(\mathrm{C}_{2} \mathrm{H}_{8} \mathrm{~N}_{2}\right)\right],\left[\mathrm{Pd}(\mathrm{Cl})_{2}\left(\mathrm{C}_{3} \mathrm{H}_{10} \mathrm{~N}_{2}\right)\right]$ e $\left[\mathrm{Pd}_{2}(\mathrm{Cl})_{4}\left(\mathrm{C}_{10} \mathrm{H}_{27} \mathrm{~N}_{4}\right)\right] \quad 115$

5.3.1 Geral 115

5.3.2. Ponto de Fusão 116

5.3.3. Análise Elementar (CHN) 117

5.3.4. Análise Termogravimétrica 119 
5.3.5. Espectroscopia no Infravermelho

5.3.6. Comparação entre o estudo dos complexos $\left[\mathrm{Pd}\left(\mathrm{Cl}_{2}\left(\mathrm{C}_{2} \mathrm{H}_{8} \mathrm{~N}_{2}\right)\right]\right.$ e $\left[\mathrm{Pd}(\mathrm{Cl})_{2}\left(\mathrm{C}_{3} \mathrm{H}_{10} \mathrm{~N}_{2}\right)\right]$ no estado sólido e em solução

6. Conclusão 125

6.1. Complexos do tipo PA[ZnCl 4$]$

6.2. Complexos do tipo $\mathrm{PA}\left[\mathrm{NiCl}_{4}\right]$

6.3.Complexos de Paládio (II) - $\left[\mathrm{Pd}(\mathrm{Cl})_{2}\left(\mathrm{C}_{2} \mathrm{H}_{8} \mathrm{~N}_{2}\right)\right]$, $\left[\mathrm{Pd}(\mathrm{Cl})_{2}\left(\mathrm{C}_{3} \mathrm{H}_{10} \mathrm{~N}_{2}\right)\right]$ e $\left[\mathrm{Pd}_{2}(\mathrm{Cl})_{4}\left(\mathrm{C}_{10} \mathrm{H}_{27} \mathrm{~N}_{4}\right)\right]$

8. Anexos

8.1 Anexo A 


\section{Lista de Figuras}

Figura 2.1. Estrutura da 1,2 diaminoetano 22

Figura 2.2. Estrutura da 1,3 diaminopropano 22

Figura 2.3. Estrutura da 1,4 diaminobutano 22

Figura 2.4. Estrutura da N-(3aminopropil)butano-1,4-diamino 22

Figura 2.5. Estrutura da N,N'-bis(3aminopropil)butano-1,3-diamino 22

Figura 2.6. Biossíntese das poliaminas 27

Figura 2.7. Degradação das poliaminas 28

Figura 3.1. Algumas reações catalisadas por enzimas de zinco 34

Figura 3.2. Sítio ativo da enzima anidrase carbônica 35

Figura 3.3. Estrutura enzima anidrase carbônica 36

Figura 3.4. Mecanismo catalítico da enzima 37

Figura 3.5. Oxidação de álcool catalisada pela álcool desidrogenase $\quad 38$

Figura 3.6. Coordenação do zinco catalítico e do zinco estrutural 38

Figura 3.7. Complexo formado entre o íon níquel e a dimetilglioxima $\quad 44$

Figura 3.8. Apresentação esquemática do termocromismo 46

Figura 3.9. Reações catalisadas por enzimas contendo íon níquel 48

Figura 3.10. Estrutura de uma urease bacteriana 51

Figura 3.11. Proposta para o mecanismo de reação da urease 51

Figura 3.12. Estrutura do sítio catalítico de uma NiFe hidrogenase 52

Figura 3.13. Proposta de mecanismo de oxidação de $\mathrm{H}_{2}$, envolvendo ciclo entre os estados de oxidação +1 e +2

Figura 3.14. Proposta de mecanismo de oxidação de $\mathrm{H}_{2}$, envolvendo ciclo entre os estados de oxidação $+2 \mathrm{e}+3$

Figura 3.15. Proposta de mecanismo de reação de Acetil-CoA isomerase 54

Figura 3.16. Estrutura do complexo $[\mathrm{Pd}(\mathrm{En})(\text { Pyridine }) \mathrm{Cl}]^{+}$

Figura 3.17. Estrutura do complexo $\left[\mathrm{Pd}_{2}(\mathrm{~S}(-) \mathrm{C} 2, \mathrm{~N}-\mathrm{dmpa})_{2}(\mu-\mathrm{dppe}) \mathrm{Cl}_{2}\right] 57$

Figura 3.18. Estrutura do complexo $\left[\mathrm{Pd}_{2}(\mathrm{Cl})_{4}(\mathrm{Put})_{2}\right]$

Figura 3.19. Estrutura do complexo $\left[\mathrm{Pd}_{2}(\mathrm{Cl})_{4}(\mathrm{Spm})\right]$ 
Figura 4.1. Estrutura da 1,2 diaminoetano

Figura 4.2. Estrutura da 1,3 diaminopropano 62

Figura 4.3. Estrutura da 1,4 diaminobutano 62

Figura 4.4. Estrutura da N-(3aminopropil)butano-1,4-diamino 62

Figura 4.5. Estrutura da N,N'-bis(3aminopropil)butano-1,3-diamino 62

Figura 5.1. Estrutura do ânion complexo tetraclorozincato

Figura 5.2. Diagrama dos orbitais moleculares do complexo poliamina[ZnCl$]$

Figura 5.3. Estrutura do ânion complexo tetraclorozincato tendo a poliamina como contra-íon

Figura 5.4. Esquema para ilustração do sistema 1:1 na solução do complexo

Figura 5.5. Estrutura do composto de fórmula molecular $\mathrm{C}_{2} \mathrm{H}_{10} \mathrm{~N}_{2} \mathrm{Cl}_{4} \mathrm{Zn}$, sugerido como $\mathrm{En}\left[\mathrm{ZnCl}_{4}\right]$

Figura 5.6. Estrutura do composto de fórmula molecular $\mathrm{C}_{3} \mathrm{H}_{12} \mathrm{~N}_{2} \mathrm{Cl}_{4} \mathrm{Zn}$, sugerido como $\mathrm{Tn}\left[\mathrm{ZnCl}_{4}\right]$

Figura 5.7. Estrutura do composto de fórmula molecular $\mathrm{C}_{4} \mathrm{H}_{14} \mathrm{~N}_{2} \mathrm{Cl}_{4} \mathrm{Zn}$, sugerido como Put[ZnCl$\left.{ }_{4}\right]$

Figura 5.8. Estrutura do composto de fórmula molecular $\mathrm{C}_{7} \mathrm{H}_{22} \mathrm{~N}_{3} \mathrm{Cl}_{5} \mathrm{Zn}$, sugerido como $\mathrm{Spd}\left[\mathrm{ZnCl}_{4}\right]$

Figura 5.9. Estrutura do composto de fórmula molecular $\mathrm{C}_{10} \mathrm{H}_{30} \mathrm{~N}_{4} \mathrm{Cl}_{6} \mathrm{Zn}$, sugerido como Spm[ $\left.\mathrm{ZnCl}_{4}\right]$

Figura 5.10. Comparação entre os gráficos de TGA e DTG do ligante puro putrescina e do composto Put[ $\left.\mathrm{ZnCl}_{4}\right]$

Figura 5.11. Proposta de estrutura evidenciada para o composto $\mathrm{En}\left[\mathrm{ZnCl}_{4}\right]$ a partir dos dados de TGA e DTG e outros estudos

Figura 5.12. Modos vibracionais de $\left[\mathrm{MX}_{4}\right]^{2-}$ ativos no Raman

Figura 5.13. Estrutura obtida a partir dos dados de difratometria de Raio-X para o complexo $\mathrm{En}\left[\mathrm{ZnCl}_{4}\right]$

Figura 5.14. Estrutura obtida a partir dos dados de difratometria de Raio-X para o complexo $\mathrm{Tn}\left[\mathrm{ZnCl}_{4}\right]$

Figura 5.15. Estrutura obtida a partir dos dados de difratometria de Raio-X para o complexo Put[ZnCl 4$]$ 
Figura 5.16. Óleo obtido durante a síntese do composto $\mathrm{Spd}\left[\mathrm{ZnCl}_{4}\right] \quad 98$

Figura 5.17. Estrutura do ânion complexo tetracloroniquelato 99

Figura 5.18. Estrutura do ânion complexo tetracloroniquelato 99

Figura 5.19. Disposição dos orbitais moleculares no complexo nas diversas geometrias

Figura 5.20. Diagrama dos orbitais moleculares do complexo poliamina[ $\left.\mathrm{NiCl}_{4}\right]$ 101

Figura 5.21. Fusão do complexo $\mathrm{Spd}\left[\mathrm{NiCl}_{4}\right]$ em $265^{\circ} \mathrm{C}$ 102

Figura 5.22. Esquema para ilustração do sistema $1: 1$ na solução do complexo $\mathrm{En}\left[\mathrm{NiCl}_{4}\right]$ 103

Figura 5.23. Estrutura do composto de fórmula molecular $\mathrm{C}_{2} \mathrm{H}_{10} \mathrm{~N}_{2} \mathrm{Cl}_{4} \mathrm{Ni}$, sugerido como $\mathrm{En}\left[\mathrm{NiCl}_{4}\right]$ 105

Figura 5.24. Estrutura do composto de fórmula molecular $\mathrm{C}_{3} \mathrm{H}_{12} \mathrm{~N}_{2} \mathrm{Cl}{ }_{4} \mathrm{Ni}$, sugerido como $\mathrm{Tn}\left[\mathrm{NiCl}_{4}\right]$ 105

Figura 5.25. Estrutura do composto de fórmula molecular $\mathrm{C}_{4} \mathrm{H}_{14} \mathrm{~N}_{2} \mathrm{Cl}_{4} \mathrm{Ni}$, sugerido como Put[NiCl 4 105

Figura 5.26. Estrutura do composto de fórmula molecular $\mathrm{C}_{7} \mathrm{H}_{22} \mathrm{~N}_{3} \mathrm{Cl}_{5} \mathrm{Ni}$, sugerido como $\mathrm{Spd}\left[\mathrm{NiCl}_{4}\right]$ 105

Figura 5.27. Estrutura do composto de fórmula molecular $\mathrm{C}_{10} \mathrm{H}_{30} \mathrm{~N}_{4} \mathrm{Cl}_{6} \mathrm{Ni}$, sugerido como Spm[ $\left[\mathrm{NiCl}_{4}\right]$

Figura 5.28. Proposta de estrutura evidenciada para o composto $\mathrm{En}\left[\mathrm{NiCl}_{4}\right]$ a partir dos dados de TGA e DTG e outros estudos 109

Figura 5.29. Termocromismo observado no complexo $\mathrm{Spd}\left[\mathrm{NiCl}_{4}\right] \quad 114$ Figura 5.30. Efeito de um campo cristalino quadrado planar nas energias dos orbitais $d$

Figura 5.31. Estrutura do composto de fórmula molecular $\left[\mathrm{Pd}(\mathrm{Cl})_{2}\left(\mathrm{C}_{2} \mathrm{H}_{8} \mathrm{~N}_{2}\right)\right]$

Figura 5.32. Estrutura do composto de fórmula molecular $\left[\mathrm{Pd}(\mathrm{Cl})_{2}\left(\mathrm{C}_{3} \mathrm{H}_{10} \mathrm{~N}_{2}\right)\right]$

Figura 5.33. Estrutura do composto de fórmula molecular $\left[\mathrm{Pd}_{2}(\mathrm{Cl})_{4}\left(\mathrm{C}_{10} \mathrm{H}_{27} \mathrm{~N}_{4}\right)\right]$ 


\section{Lista de Tabelas}

Tabela 2.1. Algumas poliaminas biológicas e suas respectivas fórmulas químicas

Tabela 3.1. Características especiais do íon zinco 32

Tabela 3.2. Valores normais de zinco no organismo 41

Tabela 4.1. Dados gerais das poliaminas 63

Tabela 4.2. Dados gerais dos complexos 65

Tabela 4.3. Dados gerais dos complexos 68

Tabela 4.4. Dados gerais dos complexos 71

Tabela 5.1. Ponto de fusão dos complexos e das aminas puras $\quad 75$ Tabela 5.2. Condutividade dos complexos, do sal cloreto de zinco e das aminas livres 76

Tabela 5.3. Análise elementar e absorção atômica dos complexos $\quad 78$ Tabela 5.4. Proposta de fragmentação dos compostos poliamina[ZnCl $\left.{ }_{4}\right]$

Tabela 5.5. Freqüências vibracionais dos compostos poliamina[ZnCl 4$]$, na região de alta freqüência

Tabela 5.6. Freqüências vibracionais dos compostos poliamina[ZnCl 4 ], na região de baixa freqüência

Tabela 5.7. Algumas freqüências vibracionais dos compostos poliamina[ $\left.\mathrm{ZnCl}_{4}\right]$, ativos no Raman

Tabela 5.8. Comprimento de onda e absortividade molar verificada para os compostos poliamina[ZnCl $\left.{ }_{4}\right]$

Tabela 5.9. Dados de ressonância magnética nuclear de ${ }^{1} \mathrm{H}$ e ${ }^{13} \mathrm{C}$ das poliaminas em água deuterada

Tabela 5.10. Dados de ressonância magnética nuclear de ${ }^{1} \mathrm{H}$ dos complexos em água deuterada 
Tabela 5.11. Dados de ressonância magnética nuclear de ${ }^{13} \mathrm{C}$ dos complexos em água deuterada 94

Tabela 5.12. Ponto de fusão dos complexos e das aminas livres 102 Tabela 5.13. Condutividade dos complexos, do sal cloreto de níquel e das aminas livres 103

Tabela 5.14. Análise elementar e absorção atômica dos complexos 104 Tabela 5.15. Proposta de fragmentação dos compostos poliamina[NiCl $\mathrm{Ni}_{4} \quad 108$

Tabela 5.16. Freqüências vibracionais dos compostos poliamina[NiCl 4 ], na região de alta freqüência

Tabela 5.17. Freqüência vibracional do grupamento $\mathrm{OH}$ referente a hidratação dos compostos poliamina[ $\left[\mathrm{NiCl}_{4}\right]$

Tabela 5.18. Freqüências vibracionais dos compostos poliamina[NiCl 4 ], na região de baixa freqüência

Tabela 5.19. Alguns modos vibracionais dos compostos poliamina[NiCl $]$, ativos no Raman

Tabela 5.20. Ponto de fusão dos complexos de paládio (II) e das aminas puras

Tabela 5.21. Análise elementar dos complexos

Tabela 5.22. Proposta de fragmentação dos complexos $\left[\mathrm{Pd}(\mathrm{Cl})_{2}\left(\mathrm{C}_{2} \mathrm{H}_{8} \mathrm{~N}_{2}\right)\right]$, $\left[\mathrm{Pd}(\mathrm{Cl})_{2}\left(\mathrm{C}_{3} \mathrm{H}_{10} \mathrm{~N}_{2}\right)\right]$ e $\left[\mathrm{Pd}_{2}\left(\mathrm{Cl}_{4}\left(\mathrm{C}_{10} \mathrm{H}_{27} \mathrm{~N}_{4}\right)\right]\right.$

Tabela 5.23. Freqüências vibracionais dos complexos de paládio (II), na região de alta freqüência

Tabela 5.24. Freqüências vibracionais dos complexos de paládio (II), na região de baixa freqüência 


\section{Lista de Símbolos}

PA - Poliamina

En - Etilenodiamina

Tn - Diaminopropano

Put - Diaminobutano

Spd - Espermidina

Spm - Espermina

$\mathrm{En}\left[\mathrm{ZnCl}_{4}\right]$ - Tetraclorozincato de etilenodiamina

$\mathrm{Tn}\left[\mathrm{ZnCl}_{4}\right]$ - Tetraclorozincato de diaminopropano

Put $\left[\mathrm{ZnCl}_{4}\right]$ - Tetraclorozincato de diaminobutano

$\mathrm{Spd}\left[\mathrm{ZnCl}_{4}\right]$ - Tetraclorozincato de espermidina

Spm[ $\left.\mathrm{ZnCl}_{4}\right]$ - Tetraclorozincato de espermina

$\mathrm{En}\left[\mathrm{NiCl}_{4}\right]$ - Tetracloroniquelato de etilenodiamina

$\mathrm{Tn}\left[\mathrm{NiCl}_{4}\right]$ - Tetracloroniquelato de diaminopropano

Put $\left[\mathrm{NiCl}_{4}\right]$ - Tetracloroniquelato de diaminobutano

Spd[ $\left.\mathrm{NiCl}_{4}\right]$ - Tetracloroniquelato de espermidina

$\mathrm{Spm}\left[\mathrm{NiCl}_{4}\right]$ - Tetracloroniquelato de espermina

$\left[\mathrm{Pd}(\mathrm{Cl})_{2}\left(\mathrm{C}_{2} \mathrm{H}_{8} \mathrm{~N}_{2}\right)\right]$ - Dicloroetilenodiaminopaládio (II)

$\left[\mathrm{Pd}(\mathrm{Cl})_{2}\left(\mathrm{C}_{3} \mathrm{H}_{10} \mathrm{~N}_{2}\right)\right]$ - Diaminopropanodicloropaládio (II)

$\left[\mathrm{Pd}_{2}\left(\mathrm{Cl}_{4}\left(\mathrm{C}_{10} \mathrm{H}_{27} \mathrm{~N}_{4}\right)\right]\right.$ - Espermidinatetraclorodipaládio (II)

TG - Análise termogravimétrica

DTG - Derivada da curva termogravimétrica

RMN - Ressonância Magnética Nuclear

$v_{s}$ - Deformação axial simétrica

$\mathrm{d}_{\mathrm{as}}$ - Deformação angular assimétrica

e - Absortividade molar

$\mathrm{O}_{\mathrm{h}}$ - Simetria dos compostos octaédricos

$T_{d}$ - Simetria dos compostos tetraédricos

$\mathrm{D}_{4 \mathrm{~h}}$ - Simetria dos compostos quadrado planares 
"Confie no Senhor de todo o coração e não se apóie em sua própria inteligência. Lembre-se de Deus em tudo o que fizer, e Ele lhe mostrará o caminho certo." 